\title{
Modelling growth of Antarctic krill. I. Growth trends with sex, length, season, and region
}

\author{
So Kawaguchi ${ }^{1, *}$, Steven G. Candy ${ }^{1}$, Robert King ${ }^{1}$, Mikio Naganobu ${ }^{2}$, Stephen Nicol ${ }^{1}$ \\ ${ }^{1}$ Australian Antarctic Division, Department of Environment and Heritage, 203 Channel Highway, Kingston, Tasmania 7050, Australia \\ ${ }^{2}$ National Research Institute of Far Seas Fisheries, 5-7-1 Orido, Shimizu-ku, Shizuoka-shi, Shizuoka 424-8633, Japan
}

ABSTRACT: Growth trends of Antarctic krill with sex, length, season, and region as independent variables were modelled with a linear mixed model (LMM) using $10 \mathrm{yr}$ of accumulated instantaneous growth rate (IGR) measurements. A model of inter-moult period (IMP) as a function of temperature, required to convert IGR to daily growth rate, was fitted to data from published constant-temperature rearing studies; this model was used to predict seasonal IMP using a model of the average sea surface temperature seasonal trend for each region. Smaller krill exhibited higher growth rates and, in general, we observed a progressive decrease in IGR and daily growth with increasing size (from over $0.2 \mathrm{~mm} \mathrm{~d}^{-1}$ down to $0.05 \mathrm{~mm} \mathrm{~d}^{-1}$ for 20 and $50 \mathrm{~mm}$ krill, respectively, in December in the Indian Ocean sector of the Southern Ocean). IGR decreased from summer to autumn, with small to negative values predominating across all length classes by autumn. December was a period of rapid growth in the Indian Ocean sector of the Southern Ocean, whereas a similar peak in growth rates appeared to occur a few months earlier in the southwest Atlantic sector. Significantly lower growth rates were exhibited by females in January and February (e.g. 0.063 and $0.050 \mathrm{~mm} \mathrm{~d}^{-1}$ for $40 \mathrm{~mm}$ females) compared to males (0.119 and $0.090 \mathrm{~mm} \mathrm{~d}^{-1}$ for $40 \mathrm{~mm}$ males) in the Indian Ocean sector. Since these estimates were based on growth measurements of individual animals, they may reflect the occurrence of sex-differentiated growth patterns in the natural environment. Growth rate differences between sexes suggested that growth rate estimates based on composite length frequency distributions without sex differentiation may be problematic.

KEY WORDS: Antarctic krill $\cdot$ Growth $\cdot$ Instantaneous growth rate $\cdot$ IGR

Resale or republication not permitted without written consent of the publisher

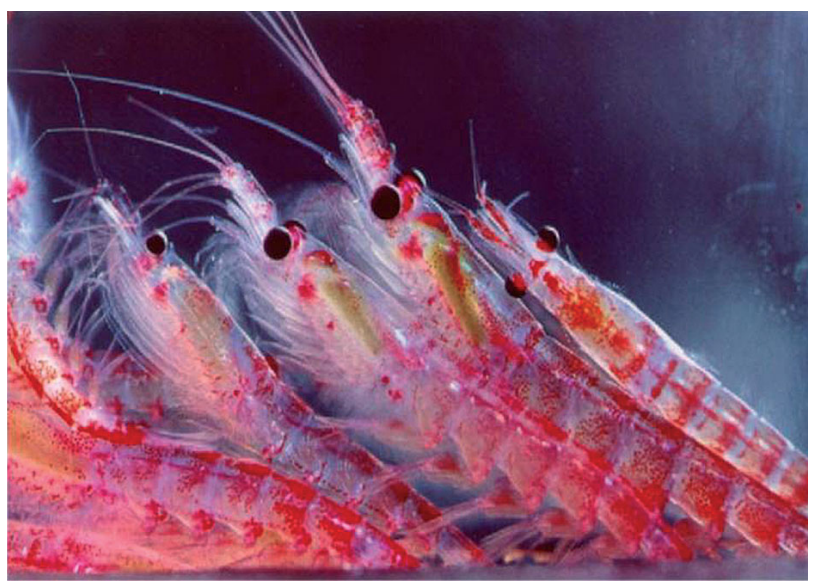

Antarctic krill Euphausia superba forms the staple diet of many species of seals, whales, fish, squid, penguins and other seabirds. The Commission for the Conservation of Antarctic Marine Living Resources sets conservative, or precautionary, fishing limits on krill, which allows for the needs of its predators in the ecosystem. Precautionary catch limits are calculated using information on the biology of krill including growth rate.

Photo: @1999 Tadashi Mizowaki/Asahi Shimbun. Used by permission

\section{INTRODUCTION}

Antarctic krill Euphausia superba is a keystone species of the Antarctic marine ecosystem. Information on krill growth is extremely important in order to link carbon flow from primary producers to the apex predators. At the same time, krill growth is one of the most important parameters required for ecosystem management under the Commission for Conservation of Antarctic Marine Living Resources (CCAMLR) regime (Constable \& de la Mare 1996). 
Understanding growth of krill in the wild has been a problem since the days of the Discovery Investigation in the 1920s (Ross \& Quetin 2003). Much attention continues to be directed at understanding the growth rate and age-at-size of Antarctic krill because of the importance of these parameters to both energetics and population dynamics (Quetin et al. 1994). In general, traditional length-frequency analysis of repeated sampling has been used; however, this method is based on the assumption that the series of krill sampled are from the same population, which is difficult to verify for pelagic organisms (Nicol 2000). An alternative approach is to generate an energetically based model using laboratory derived energetic and physiological parameters (Hoffman \& Lascara 2000). Another approach is to measure the instantaneous growth rate (IGR), which utilises data on length changes from live krill after Quetin \& Ross (1991). This method was modified by Nicol et al. (1992) to be more efficient, thus allowing an increase in the sample size. The advantage of this method is that it is based on the observed growth of individuals measured at moulting, and can also be related to ambient environmental conditions (Ross et al. 2000). The IGR technique is beginning to provide a large amount of data on growth; however, extensive use of data derived from this method (e.g. detailed examination of growth characteristics and modelling krill growth trajectories) is yet to be attempted (Nicol 2000). The data on IGR used in this study was collected in 2 regions of the Southern Ocean-the Indian Ocean sector and the southwest Atlantic sector (Fig. 1) - with the bulk of the data coming from the Indian Ocean sector.

The aims of this study were: (1) to develop statistical models to summarise a large amount of IGR data and to convert these summary statistics into daily growth rates using a model of inter-moult period, and (2) to compare values with other published growth rates, and to discuss characteristics of krill growth in field environments and its implications for krill management. The models described here were extended and applied by Candy \& Kawaguchi (2006, this volume) in order to predict a population-average growth trajectory for total length for krill in the Indian Ocean sector.

\section{MATERIALS AND METHODS}

Data incorporated into the modelling process were collected from the Indian Ocean sector of the Southern Ocean by RSV 'Aurora Australis' during 10 austral summer seasons (December to April) from 1992/1993 to 2002/2003, and from the southwest Atlantic sector by RV 'Kaiyo-Maru' between November and February 1999/2000 (Fig. 1, Table 1).

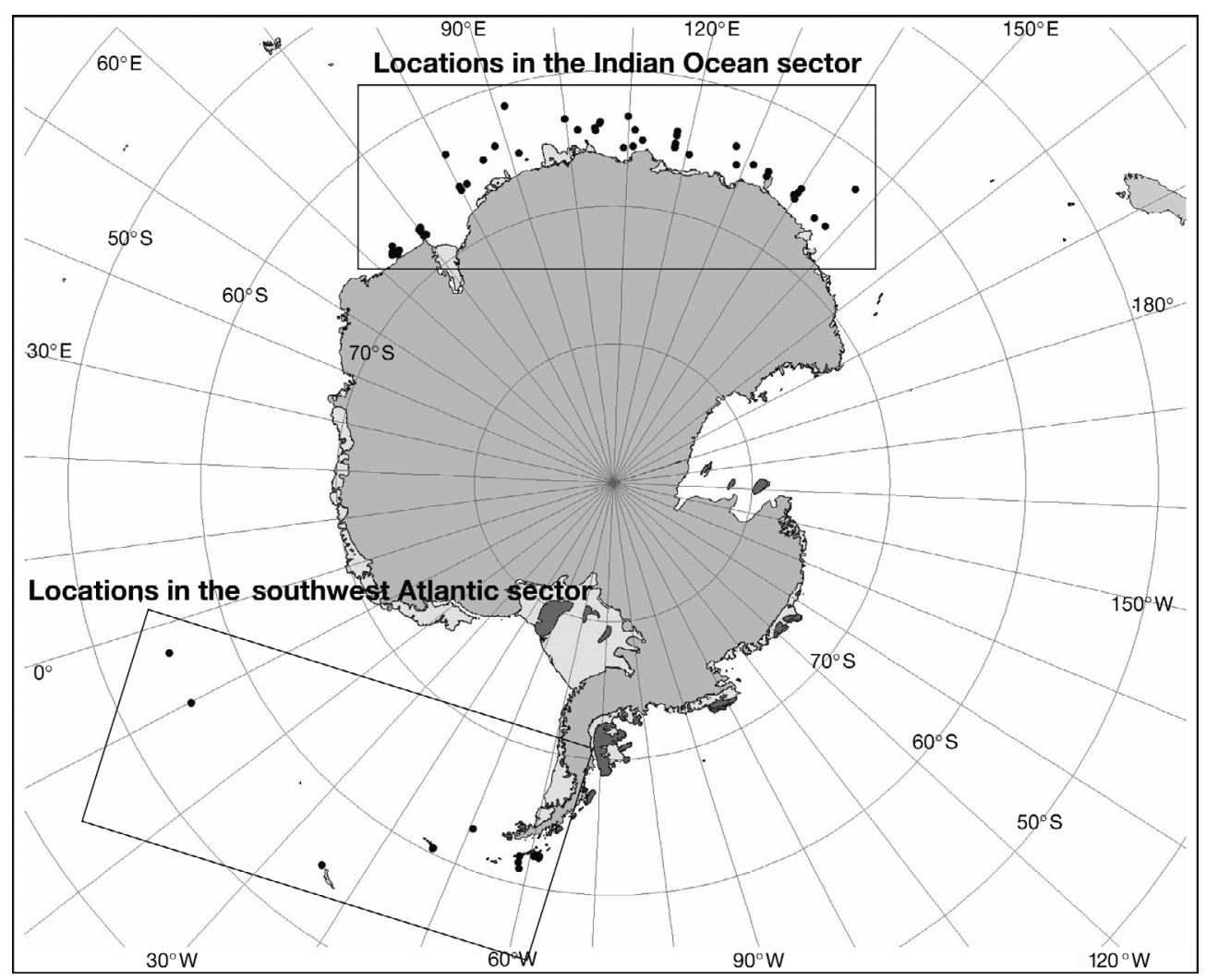

Fig. 1. Locations $(\bullet)$ where instantaneous growth rate experiments were conducted. Refer to Table 1 for positions in detail 
Table 1. Summary of IGR experiments conducted. S: still water system; F: flow through system; Valid: number of data used for modelling in this study; na: not available

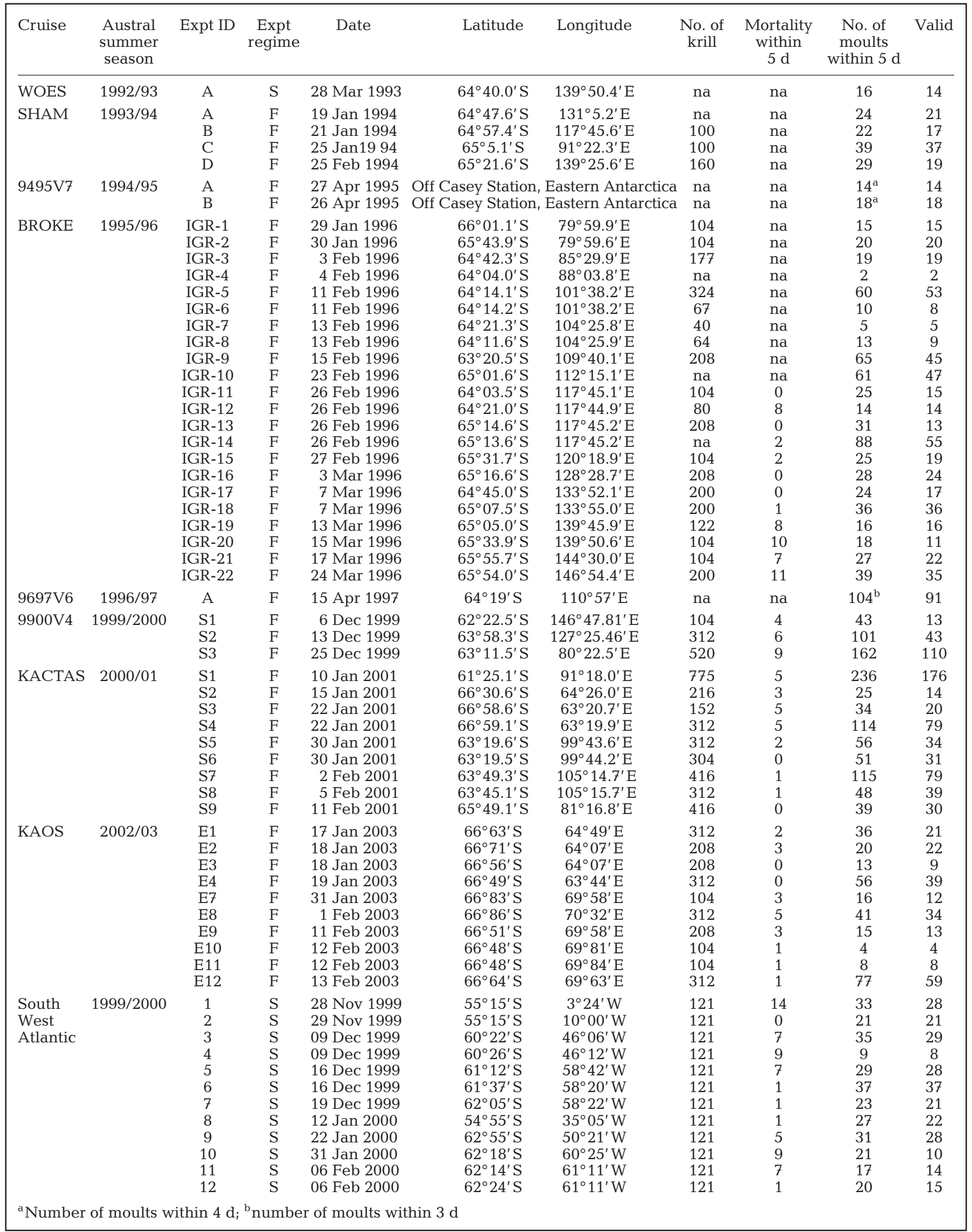


Crustaceans grow or shrink in size as they moult. Length of discarded moults represent length of animals before their moulting events. Therefore, by measuring length of discarded moult and length of animal after moult, growth increments at the time of moult can be obtained. IGR is defined as the growth increment expressed as a proportion of pre-moult total length (TL). IGR can be converted into daily growth rate for a given value of TL by calculating absolute growth increment and dividing by an estimate of inter-moult period (IMP).

The IGR technique depends on the collection of live krill in good condition. Krill were caught with an RMT-8 net (Baker et al. 1973) and individual freshly caught animals were randomly selected from the catch and immediately transferred to individual jars. They were then maintained onboard and checked regularly for moults for up to $5 \mathrm{~d}$ following capture. The experiments were run either in a still seawater system (unfiltered) using $2 \mathrm{l}$ jars maintained at $0^{\circ} \mathrm{C}$, or a flowthrough seawater system which used $250 \mathrm{ml}$ jars with small holes to allow water exchange in a large (1000 l) flow-through tank of seawater maintained at ambient ocean temperature. In both cases, no additional food was provided. The latter system allowed a sample size of over 1000 krill per experiment, a much larger sample size than had been available for earlier studies (Nicol 2000). Each krill was checked daily after capture to ascertain whether it had moulted. If an animal had moulted, then the animal and its moult were collected and frozen in liquid nitrogen or at $-85^{\circ} \mathrm{C}$ to be measured back ashore. The growth rate was estimated from the difference in length of the uropod of the moult and that of the whole post-moult krill. Where available, the overall mortality rate was estimated to be $1.8 \%$ during the $5 \mathrm{~d}$ maintenance period.

For krill captured during the austral summer 1993/1994 and onwards, the total length of uropod exopodites were measured on both the left and right sides for both the animal and the moult using image analysis. Images were captured by colour video camera (Sony CCD-IRIS/RGB), and length measurements were made using Sigma Scan Pro 5.0 ${ }^{\circledR}$ image analysis software. Standard deviation of the measurements was $0.02 \mathrm{~mm}(\mathrm{n}=10)$. For krill collected during the austral summer 1992/1993, measurements were made using digital callipers. For all measurements, the proportional change in uropod length was calculated using the following equation:

$$
\mathrm{IGR}=\frac{[(\text { RUro }- \text { RMou })+(\text { LUro }- \text { LMou })] / 2}{(\text { RMou }+ \text { LMou }) / 2}
$$

where RUro is the length of animal's right uropod, LUro is the length of animal's left uropod, RMou is the length of the moulted right uropod, and LMou is the length of the moulted left uropod.
This provided a rate of growth for each animal that moulted during the course of the experiment. Sometimes, one of the uropods or moulted uropods of an animal was damaged and therefore was not measured. In these cases, growth measurements were based on a single uropod and moult pair. If both uropods were damaged then the animal was excluded from the study.

The IGR value obtained from the uropod lengths was assumed to apply to the pre-moult TL of the animal; TL (from tip of the rostrum to tip of uropod excluding setae; SL1 of Mauchline 1980) of post-moult animals was measured for experiments undertaken in the southwest Atlantic Sector and pre-moult TL was calculated as post-moult TL divided by $(1+$ IGR). For experiments conducted in the Indian Ocean sector, postmoult TL was not measured so pre-moult TL was calculated from the moulted uropod length (UL) of the moult using the following equation (Hollander 2001):

Pre-moult TL $=($ moulted UL -0.1051$) / 0.1407$

All animals were sexed as males, females, or juveniles according to existence/absence of petasma/ thelycum in the post moult animals. In total, 1881 individual krill IGRs were estimated. For the Indian Ocean sector, 1156 of 1620 measurements were taken during the January to February period; for the southwest Atlantic sector, 123 of 261 measurements were taken in December. For both areas, percentages of measurements taken from juveniles, females, and males were close to 44,36 , and $20 \%$, respectively.

IMP for different temperature regimes were obtained from published studies (Murano et al. 1979, Ikeda \& Dixon 1982, Poleck \& Denys 1982, Morris \& Keck 1984, Ikeda et al. 1985, Ikeda 1987, Buchholz 1991).

Model description. IGR model: IGR was modelled using a linear mixed model (LMM) using the SAMM (Spatial Analysis Mixed Models with S-plus) set of functions (Butler et al. 2002) for S-plus (Insightful 2002) in order to account for fixed effects of REGION (Indian Ocean sector, southwest Atlantic sector), SEX (male, female, juvenile), MONTH (month of capture), and pre-moult total length class (TLC); and random effects of CRUISE and ANIMAL-WITHIN-CRUISE. We fitted the LMM to log transformed values of IGR after adding a positive value to all IGR values in order to allow the transformation to be carried out: this value was the sum of the absolute value of the minimum IGR value $(-0.0471)$ and 0.01 . Predictions of IGR from the fitted LMMs were obtained by taking the exponential of LMM predictions and subtracting 0.0571. We also included days from capture to moult (DCM) as a factor and its interaction with other factors as fixed effects in the LMM to take into account any effect due to 
captivity and maintenance condition on IGR. As an alternative to DCM (which could be 1 of 5 integers corresponding to Days 1 to 5 from capture to moult), we also defined a continuous variable as days from capture to moult minus 1 (Dm1). This variable was required to adjust all IGR values to the predicted IGR at Dm1 of 0 (i.e. single day from capture to moult) if we found that growth rate decayed with increasing Dm1 due to negative effects of captivity.

Pre-moult TL classes were $4 \mathrm{~mm}$ wide between 16 and $52 \mathrm{~mm}$, with first and last classes of 8 to $16 \mathrm{~mm}$ and 52 to $60 \mathrm{~mm}$, respectively. It was necessary to account for heterogeneous variances in model residuals at the CRUISE level by estimating separate variances for each TLC. In addition to estimating mean IGR for each combination of the fixed effects and their corresponding standard errors, means were smoothed across TLCs by fitting a cubic smoothing spline using means of pre-moult TL for each TLC as 'knot points', where pre-moult TL means were calculated across all data in the length class and denoted TLCL. The cubic smoothing spline is a combination of a linear model in TLCL and smoothed departures from linearity, which were modelled as random effects estimated at knot points defined by the TLCL values (Verbyla et al. 1999). Interpolation of mean IGR between knot points was carried out using the 'predict' function within SAMM. The minimal (significant) fixed effect model was determined by backward selection using Wald tests (Verbyla et al. 1999).

IMP model: The following model was used to predict IMP from sea surface temperature. The model was fitted using a meta-analysis of published data from: Murano et al. (1979), Ikeda \& Dixon (1982), Poleck \& Denys (1982), Morris \& Keck (1984), Ikeda et al. (1985), Ikeda (1987), and Buchholz (1991). Where individual moult times were published, these were averaged for each temperature regime in the study and the standard deviation and number of observations per temperature were calculated. For other studies, these summary statistics were already published. Data obtained from these 10 published studies are also described by Quetin et al. (1994).

Inter-moult period was fitted using the following generalized linear model (GLM) (McCullagh \& Nelder 1989):

$$
I=\exp \left[\beta_{0}+\beta_{1} \ln (T+2)\right]+\varepsilon
$$

where $I$ is inter-moult period (d), $T$ is the temperature $\left({ }^{\circ} \mathrm{C}\right)$ under which rearing took place, $\beta_{0}$ and $\beta_{1}$ are parameters to be estimated, and $\varepsilon$ is the assumed gamma error. Prior weights (i.e. reciprocal of the sample size for the particular study and temperature) were used in the fit. Eq. (1) gives a linear relationship on the log-log scale. Gamma errors accounted for an increas- ing variance of $I$ with increasing expected value. A meta-analysis using a generalized linear mixed model (GLMM) (Platt et al. 1999) to include studies as random effects was not carried out, because only 2 out of 10 studies involved more than a single temperature.

Seasonal sea surface temperature model: Seasonal temperatures, expressed as natural logarithms after adding $2^{\circ} \mathrm{C}$, were fitted using a sin curve and nonlinear ordinary least squares estimation. Eq. (2) as given below was fitted separately to data from the Indian Ocean sector and the southwest Atlantic sector:

$$
\ln (T+2)=\alpha_{0}+\frac{\alpha_{1}}{2 \pi} \sin \left[2 \pi\left(M / 12-\alpha_{2}\right)\right]
$$

where $T$ is sea surface temperature $\left({ }^{\circ} \mathrm{C}\right), M$ is month number (i.e. May $=1$, June $=2, \ldots$, April $=12$ ), and $\alpha_{0}$, $\alpha_{1}$, and $\alpha_{2}$ are parameters to be estimated. Surface temperature data (4 yr of monthly means from March 1999 to February 2003) for both the Indian Ocean sector (box bounding $65.0^{\circ} \mathrm{S}, 65.0^{\circ} \mathrm{E}$ to $64.0^{\circ} \mathrm{S}, 70.0^{\circ} \mathrm{E}$ near Prydz Bay) and the southwest Atlantic (box bounding $55.5^{\circ} \mathrm{S}, 38.5^{\circ} \mathrm{W}$ to $54.5^{\circ} \mathrm{S}, 37.0^{\circ} \mathrm{W}$ near South Georgia) (Fig. 1) were taken from NOAA satellite data (available from www.class.ncdc.noaa.gov/ nsaa/products/welcome). Each year from May to October, the relevant area of Indian Ocean sector was covered by ice; therefore, the dummy data point $-1.8^{\circ} \mathrm{C}$ was used for June, July, and August.

\section{RESULTS}

\section{IGR}

To remove any effect of DCM on IGR we fitted linear and spline terms in Dm1 and, in order to validate the final model, we compared predictions from this model with predicted means for each combination of DCM and the factors of interest. Because of many missing combinations of these factors for the southwest Atlantic sector, we carried out this validation for the Indian Ocean sector only.

Wald tests indicated that all 2-factor interactions with DCM were significant $(p<0.05)$, so only these interactions were included in the LMM along with main effects and interactions for the factors of interest as described below. Fig. 2 shows IGR predictions obtained by back-transformation of predictions from the LMM incorporating DCM for the Indian Ocean sector and the 36 to $40 \mathrm{~mm}$ TL class, for combinations of SEX, MONTH and DCM. This TL class was chosen because within this class the predicted means for all combinations of SEX, MONTH and DCM were estimable. The points (i.e. predicted means) in Fig. 2 were obtained using this LMM, whereas the curves were obtained using the alternative LMM with linear 


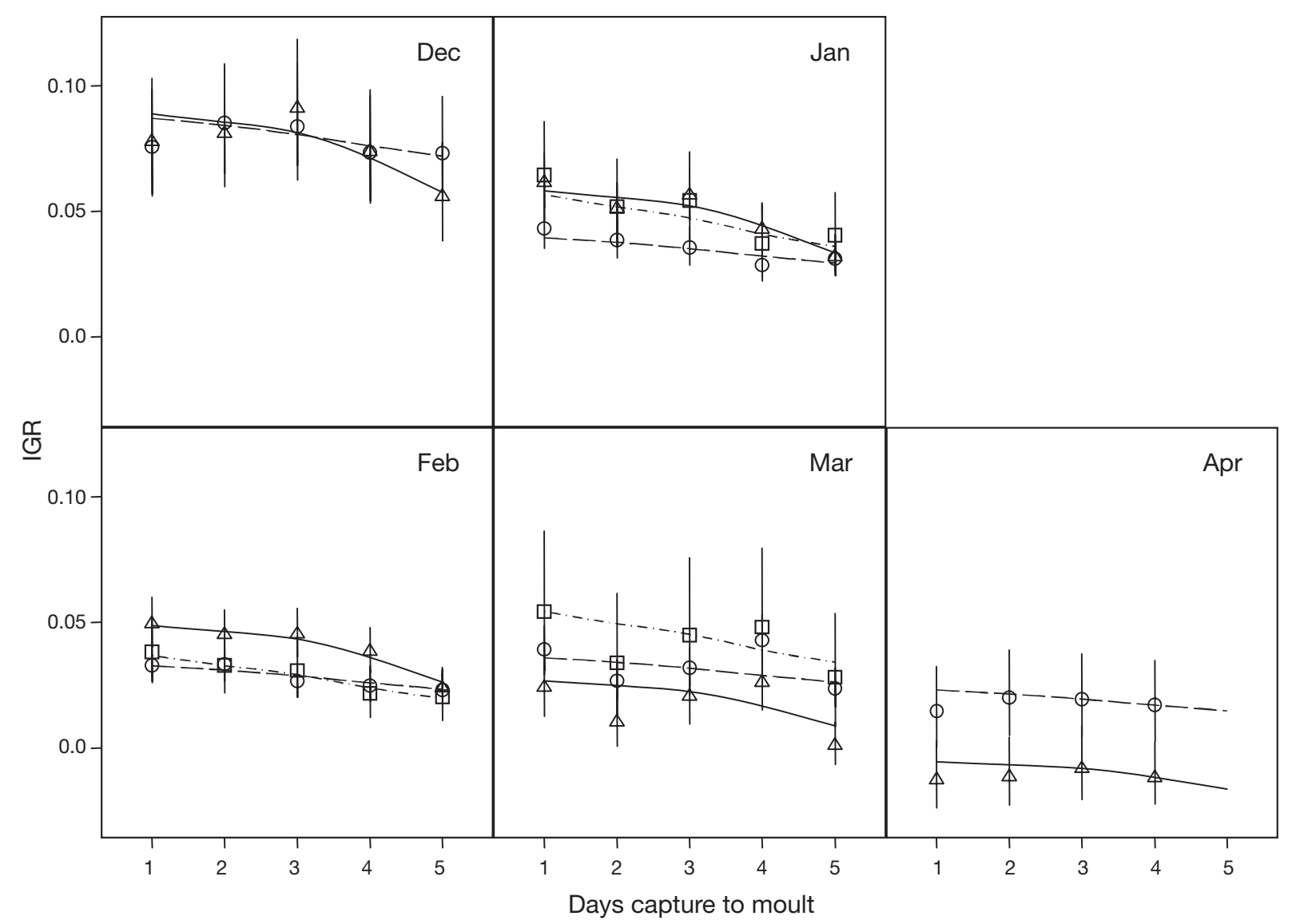

Fig. 2. Euphausia superba. Model prediction of instantaneous growth rate (IGR) with SE bars and fitted spline model for measurements taken in December to April 1 to $5 \mathrm{~d}$ after catch in the Indian Ocean sector. Juveniles: $\square, \cdot-\cdot-\cdot-$; males: $\Delta,-$; females: $0,-\ldots$

and spline terms in Dm1 for each level of SEX. The curves in Fig. 2 generally appeared to closely follow the trend in means with DCM.

For the southwest Atlantic sector, the corresponding LMM only gave a realistic trend with Dm1 when sex interactions were excluded. We then fitted a LMM to the combined dataset for both sectors with a composite factor and its interaction with Dm1, where this factor was defined with the levels 'Indian_F' (female), 'Indian_J' (juvenile), 'Indian_M' (male), and 'Atlantic'. Fig. 3 shows predicted IGR expressed as a proportion of predicted 'baseline' IGR at Day 1 versus days from capture obtained from the above LMM. For the Indian Ocean sector, IGR at Day 5 as a proportion of that at Day 1 ranged between 0.8 and 0.9 according to different levels of SEX. In contrast, IGR at Day 5 as a proportion of that at Day 1 was predicted to be as low as 0.6 for the southwest Atlantic sector. The trends were close to linear except for Indian_M, which showed a clear concave-downwards trend; however, this trend was not very different to the overall close-to-linear trend for Indian_J.
These results indicated a systematic reduction of IGR with increasing period of shipboard maintenance from as early as Day 2, and therefore suggested that it was necessary to remove these trends in order to validly investigate IGR patterns with the factors of interest since DCM is effectively a 'nuisance' factor. We did this by standardising IGR predictions to Day 1 in order

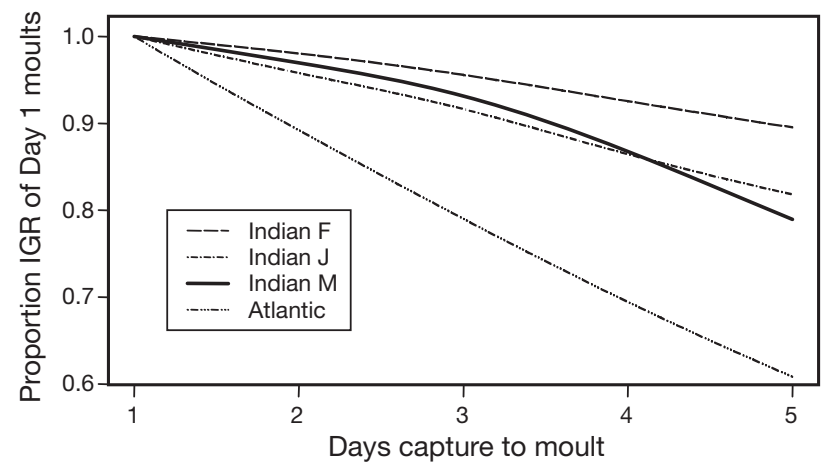

Fig. 3. Euphausia superba. Predicted instantaneous growth rate (IGR) as a proportion of IGR of Day 1 moults. F: female; J: juvenile; M: male 
to reflect natural growth as closely as possible. This standardisation involved calculating predictions of IGR at Day 1 from the fitted LMM described above and demonstrated in Fig. 3.

As far as the factors of interest were concerned, Wald tests from the fit of the LMM indicated a significant REGION $\times$ SEX $\times$ MONTH $\times$ TLC interaction $(p=$ 0.019). There was a significant increase in the variance of log transformed IGR (baseline CRUISE-level variance $=0.02058$ ) with TLC for the 20 to $24 \mathrm{~mm}$ (additional variance $=0.06425$ ), 24 to $28 \mathrm{~mm}$ (additional variance $=0.05373$ ), and 28 to $32 \mathrm{~mm}$ (additional variance $=0.01355$ ) classes, while the variance for the ANIMAL-WITHIN-CRUISE residuals was 0.06292. For the spline model, TLC was replaced by the continuous variable TLCL and the spline terms in TLCL were added to the random model. While the full REGION $\times$ SEX $\times$ MONTH $\times$ TLCL term was fitted as part of the fixed model, a reduced spline model of REGION $\times$ SEX $\times$ spline(TLCL) was required to enable the estimation algorithm to be successful.

Fig. 4 shows the plot for each region and month of predicted mean IGR by TLC, with standard error bars plotted at the mean pre-moult TL (i.e. TLCL) of each class for each sex (males, females, and juveniles). The fitted cubic smoothing splines are also shown in Fig. 4. Note that the standard errors shown incorporate the additional imprecision associated with projecting IGR measurements back to Day 1 (i.e. Dm1 = 0).

Smaller animals generally exhibited higher IGRs (Fig. 4), while IGR in both regions generally decreased from summer through to autumn. Growth trends were not as clear in the southwest Atlantic, which had much larger uncertainty around means compared to the Indian Ocean due to much smaller sample sizes for that region.

In the Indian Ocean sector, the IGR prediction for December showed the highest values, $\sim 0.03$ to $\sim 0.2$ (or $\sim 3$ to $\sim 20 \%$ ) increase in length per moult corresponding to the extremes in the length range of $50 \mathrm{~mm}$ and $20 \mathrm{~mm}$, respectively. Predictions of IGR gradually decreased as the austral summer season progressed, and by April the IGR was -0.01 to 0.02 (or -1 to $2 \%$ ) per moult within the length range $50 \mathrm{~mm}$ to $20 \mathrm{~mm}$ (Fig. 4a). A mean IGR above 0.3 (or $30 \%$ ) recorded for the 8 to $16 \mathrm{~mm}$ class for December in the Indian Ocean sector seems unrealistically high; however, this value was for a single measurement and due to a relatively short uropod length, this value should not be regarded as representative of growth for TLC.

When mean IGRs were compared across sexes in the Indian Ocean sector in December, juveniles, males, and females showed similar trends. In January, means for both juveniles and males seemed to lie on similar curves, but growth rates of females larger than $40 \mathrm{~mm}$ tended to be lower, whereas females smaller than $32 \mathrm{~mm}$ showed higher growth rates. The apparent higher growth rate of females smaller than $32 \mathrm{~mm}$ should be viewed with caution because of the large error bars. In February, females consistently showed lower growth rates compared to males. In March and April, any difference between sexes was not obvious. In the southwest Atlantic sector (Fig. 4b), differences between sexes were not clear due to small sample sizes and correspondingly large uncertainties in population means.

\section{Temperature-IMP model}

The fitted GLM (Eq. 1) explained 90.1\% of the deviance, and parameter estimates (with standard errors in parentheses) were $\hat{\beta}_{0}=3.5371(0.0658)$ and $\hat{\beta}_{1}=-0.5358(0.0529)$. Fig. 5 shows the derived IMP as a function of temperature, with both expressed on the log scale. These parameter estimates were very similar to those in Quetin et al. (1994), where $\hat{\beta}_{0}$ and $\hat{\beta}_{1}$ were 3.592 and -0.587 , respectively (corrected values, $R$. Ross pers. comm.), because the data sources that were used to fit both models were similar. In our fitting, we took into account the sample sizes and the varianceto-mean relationship for IMP.

\section{Temperature trends and seasonal IMP trends}

The parameter estimates (SE in parentheses) obtained from the fit of Eq. (2) were: for the southwest Atlantic sector, $\hat{\alpha}_{0}=1.1755(0.0138), \hat{\alpha}_{1}=-3.3202$ (0.1229), and $\hat{\alpha}_{2}=0.1435$ (0.0059); and for the Indian Ocean sector, $\hat{\alpha}_{0}=-0.3609(0.0692), \hat{\alpha}_{1}=-8.4089$ (0.5574), and $\hat{\alpha}_{2}=0.0512(0.0129)$.

Fig. 6 shows predicted temperature trends in the Indian Ocean sector and southwest Atlantic using Eq. (2) and the above parameter estimates. In the Indian Ocean sector, the temperature started to rise from October, peaked during late January, and decreased towards June. The predicted maximum was $0.5^{\circ} \mathrm{C}$ and the minimum was $-1.8^{\circ} \mathrm{C}$. In the southwest Atlantic sector, the temperature started to rise from October, peaked during late February, and decreased towards July. The predicted maximum temperature was approximately $3.2^{\circ} \mathrm{C}$, and the minimum was $0^{\circ} \mathrm{C}$. The trends for the southwest Atlantic sector were in agreement with measurements from the South Georgia region (Whitehouse et al. 1996). South Georgia demarcates the northern limit of Antarctic krill distribution, and therefore the temperature regime here could be regarded as extreme habitat conditions for this species. The main krill habitat and reproductive 

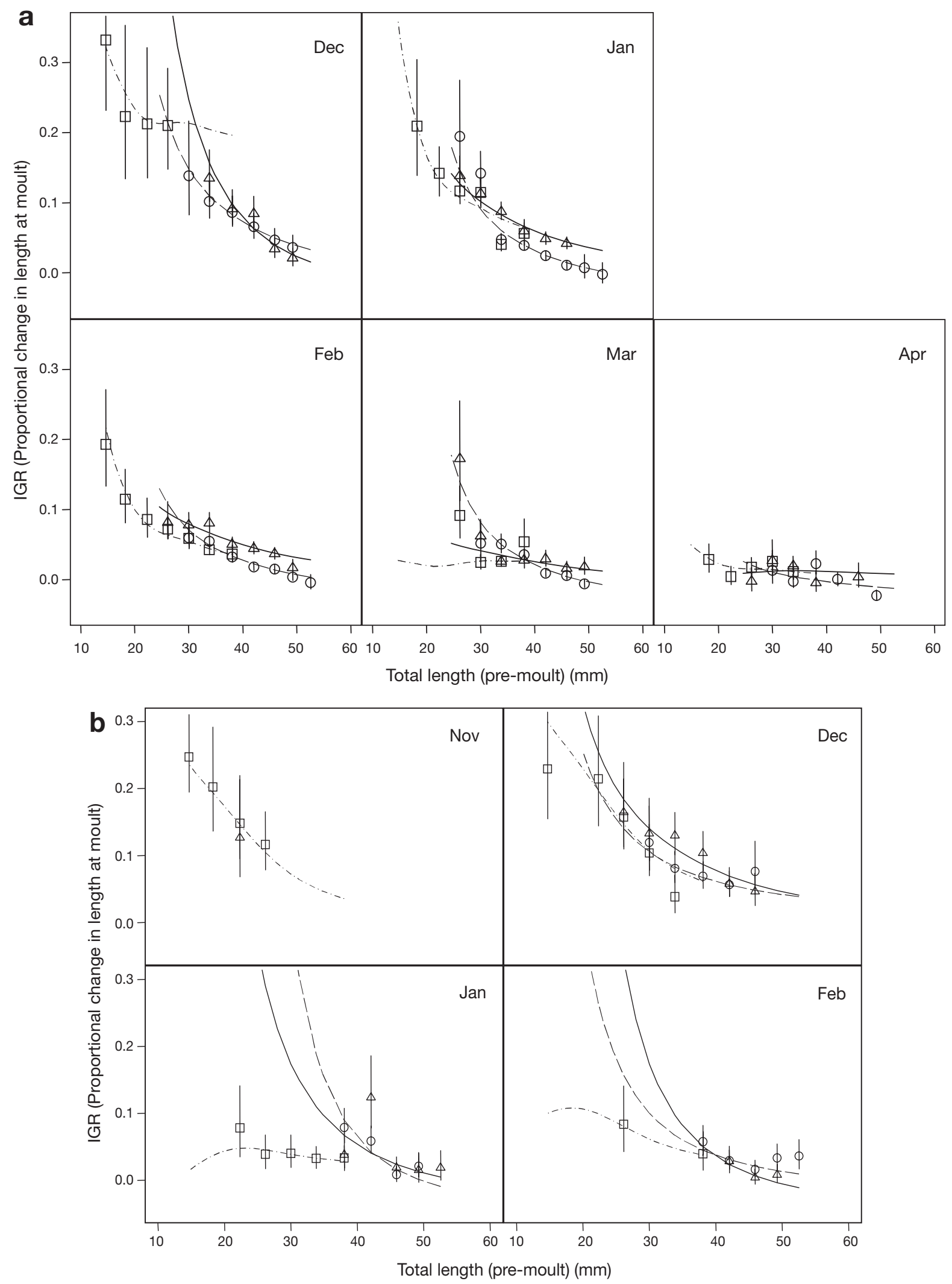

Fig. 4. Euphausia superba. Predicted IGR (proportional length increase at moult) versus pre-moult length with SE bars and fitted spline model for (a) Indian Ocean sector and (b) southwest Atlantic sector. Juveniles: $\square, \cdot-\cdot-\cdot-$; males: $\Delta,-\longrightarrow$; females: $\mathrm{O}, \ldots-\ldots$ 


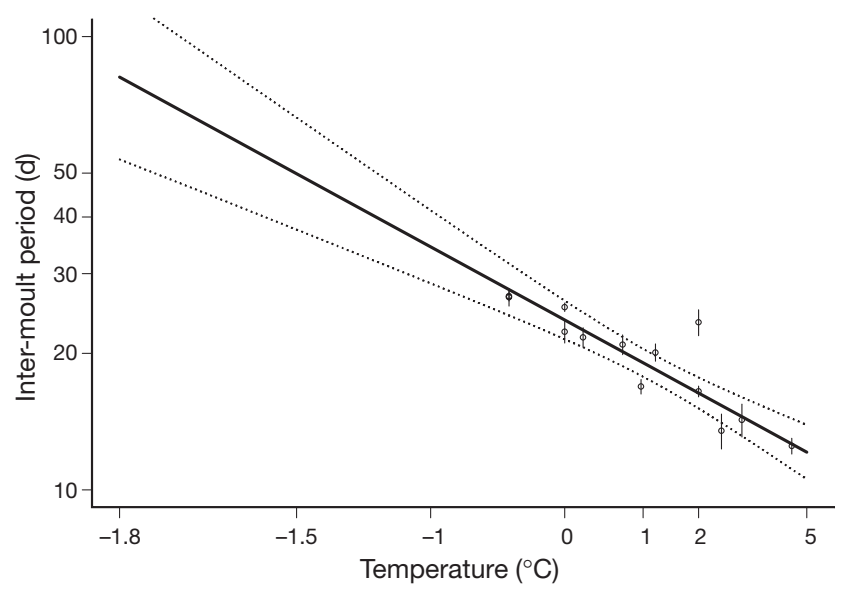

Fig. 5. Euphausia superba. Temperature versus inter-moult period, with means from laboratory experiments and fitted model (dotted lines and bars represent approximate 95\% confidence bounds)

area around the Antarctic Peninsula region may be cooler; therefore, the seasonal IMP trend line may lie between those of the 2 regions shown in Fig. 6.

Predicted IMP using predicted temperatures is also shown in Fig. 6. It ranged from $20 \mathrm{~d}$ in mid-summer up to $90 \mathrm{~d}$ in mid-winter for the Indian Ocean sector, with corresponding values of 14 and $25 \mathrm{~d}$, respectively, for the southwest Atlantic sector.

\section{Daily growth rates}

Mean daily growth rates $\left(\mathrm{mm} \mathrm{d}^{-1}\right)$ were obtained from the IGR means shown in Fig. 4 by multiplying the IGR mean by mean pre-moult TL for the TLC, and

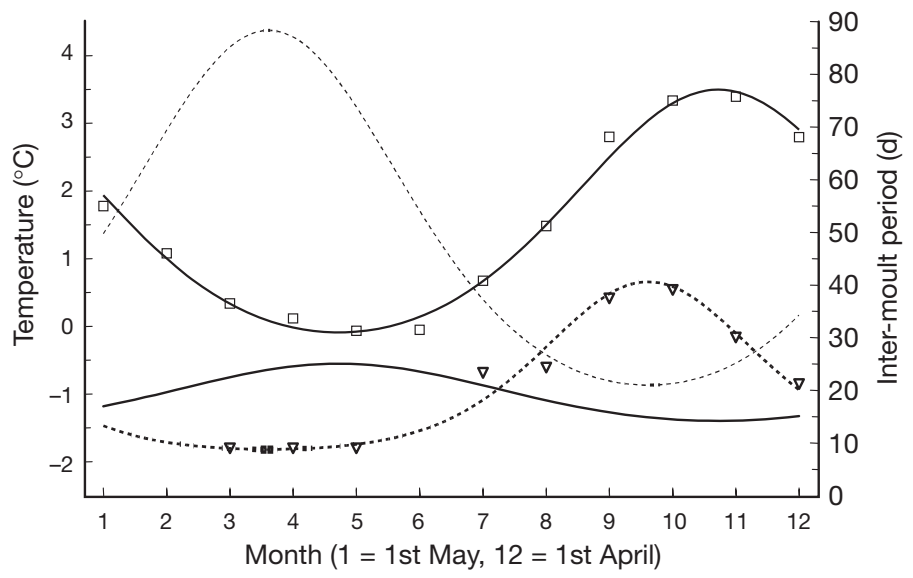

Fig. 6. Euphausia superba. Temperature trends across season and seasonal trends of inter-moult period (IMP), expressed as data and fitted model for temperature and predicted IMP. Indian Ocean sector: $\nabla$, dashed lines; southwest Atlantic sector: $\square$, solid lines

dividing by the predicted IMP for the particular region and month using the temperature predictions shown in Fig. 6. This, in effect, spreads the 'instantaneous' growth quantified by IGR uniformly across the period, from the time of the moult corresponding to the IGR until a time just prior to the next moulting event, which is the relevant IMP. Table 2 gives predicted values for mean daily growth rate for pre-moult TL values of $20,30,40$, and $50 \mathrm{~mm}$ for each sex and month for the Indian Ocean sector, and shows the IMP used in the calculation of these predictions. Fig. 7 shows mean daily growth rates, standard error bars, and spline curves obtained by scaling the corresponding IGR values shown in Fig. 4. In the Indian Ocean sector, spline curves for males and females show greater dif-

Table 2. Euphausia superba. Predicted daily growth rates $\left(\mathrm{mm} \mathrm{d}^{-1}\right)$ for $20,30,40$, and $50 \mathrm{~mm}$ krill in each month for the Indian Ocean sector. IMP: inter-moult period

\begin{tabular}{|c|c|c|c|c|c|c|c|c|c|c|}
\hline \multirow[t]{3}{*}{ Month } & \multirow{3}{*}{$\begin{array}{l}\text { IMP } \\
\text { (d) }\end{array}$} & \multirow[t]{3}{*}{ Sex } & \multicolumn{8}{|c|}{ - Pre-moult total length } \\
\hline & & & \multicolumn{2}{|c|}{$20 \mathrm{~mm}$} & \multicolumn{2}{|c|}{$30 \mathrm{~mm}$} & \multicolumn{2}{|c|}{$40 \mathrm{~mm}$} & \multicolumn{2}{|c|}{$50 \mathrm{~mm}$} \\
\hline & & & Growth & SE & Growth & SE & Growth & SE & Growth & $\mathrm{SE}$ \\
\hline \multirow[t]{3}{*}{ Dec } & 23 & Juvenile & 0.204 & 0.049 & 0.279 & 0.087 & & & & \\
\hline & & Male & & & & & 0.136 & 0.030 & 0.050 & 0.023 \\
\hline & & Female & & & & & 0.126 & 0.027 & 0.083 & 0.027 \\
\hline \multirow[t]{3}{*}{ Jan } & 20 & Juvenile & 0.168 & 0.027 & 0.139 & 0.016 & & & & \\
\hline & & Male & & & & & 0.119 & 0.015 & 0.089 & 0.019 \\
\hline & & Female & & & & & 0.063 & 0.011 & 0.015 & 0.012 \\
\hline \multirow[t]{3}{*}{ Feb } & 22 & Juvenile & 0.091 & 0.016 & 0.074 & 0.010 & & & & \\
\hline & & Male & & & & & 0.090 & 0.013 & 0.071 & 0.016 \\
\hline & & Female & & & & & 0.050 & 0.009 & 0.015 & 0.010 \\
\hline \multirow[t]{3}{*}{ Mar } & 28 & Juvenile & 0.014 & 0.020 & 0.028 & 0.007 & & & & \\
\hline & & Male & & & & & 0.036 & 0.009 & 0.025 & 0.014 \\
\hline & & Female & & & & & 0.030 & 0.007 & -0.006 & 0.008 \\
\hline \multirow[t]{3}{*}{ Apr } & 40 & Juvenile & 0.012 & 0.006 & 0.011 & 0.006 & & & & \\
\hline & & Male & & & & & 0.011 & 0.011 & 0.010 & 0.020 \\
\hline & & Female & & & & & -0.003 & 0.006 & -0.014 & 0.010 \\
\hline
\end{tabular}



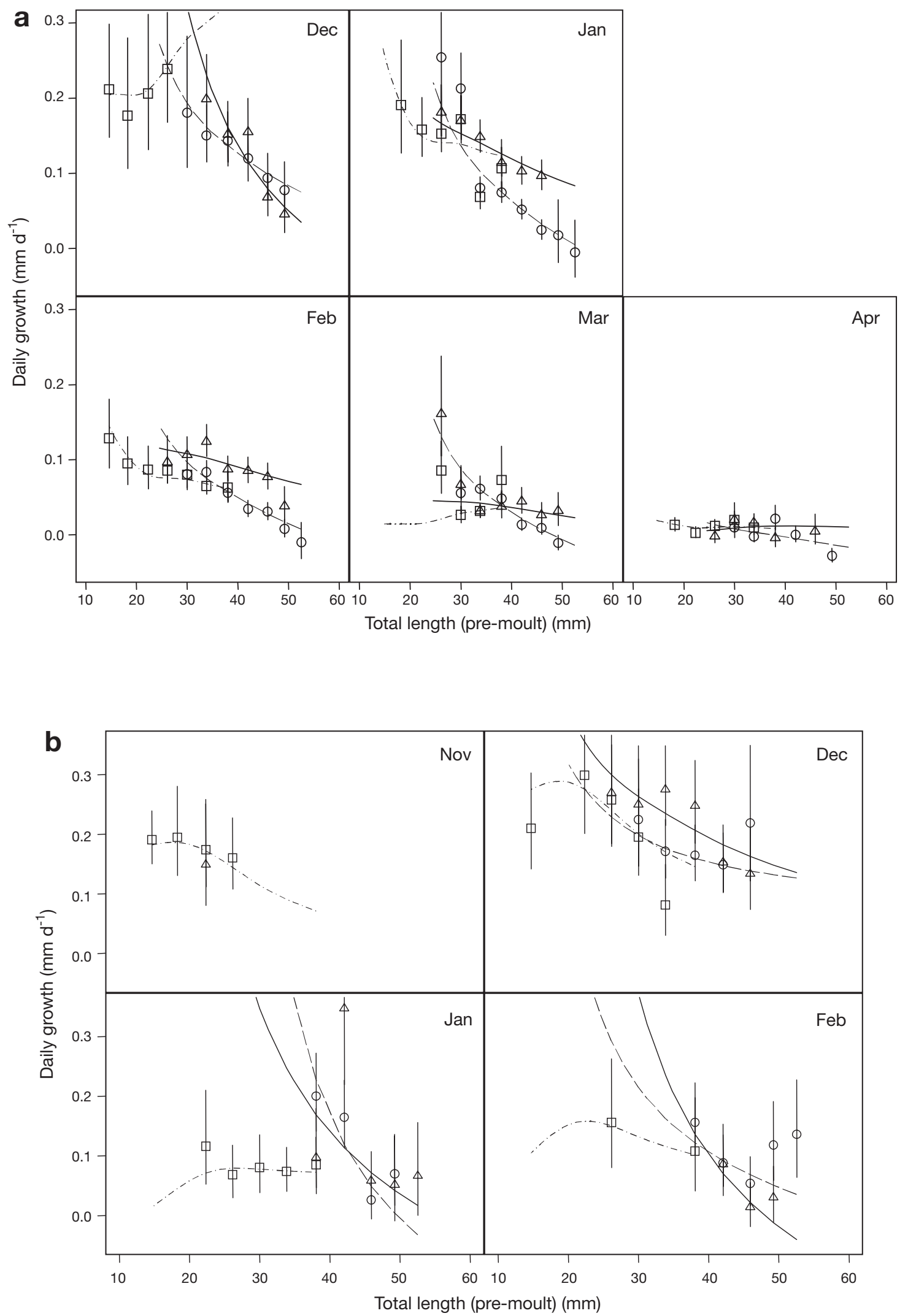

Fig. 7. Euphausia superba. Predicted daily growth rates $\left(\mathrm{mm} \mathrm{d}^{-1}\right)$ versus pre-moult length with SE bars and fitted spline model for

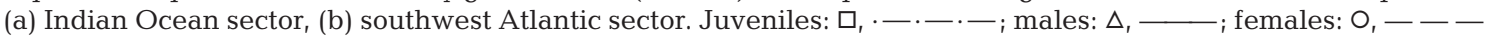


ferences for daily growth rates than IGR measurements for larger krill in January and February; however, this difference was less pronounced in smaller krill for these months (Fig. 7a). Sex differences in growth were not as obvious for southwest Atlantic krill (Fig. 7b) due to a much greater uncertainty in mean values due to small sample sizes.

\section{DISCUSSION}

\section{Effect of DCM}

The amount of time required after capture for the effect of captivity to significantly affect growth relative to growth in the wild is a critical issue for IGR growth measurements. In general, IGR measured in short term experiments are assumed to reflect natural growth rates (Quetin \& Ross 1991). Although this assumption has been tested using a limited amount of IGR data (Nicol et al. 1992), it has never been tested on a comprehensive dataset. We included Dm1 in the model for IGR simply to remove the effect of captivity on IGR, so that we could carry out valid inferences for the factors of interest. Since there are clear decreasing trends in IGR from Day 2 onwards (Figs. 2 \& 3), ignoring the effect of days from capture effectively averages across these trends and, therefore, would result in conservative predictions of mean IGR. Our investigation confirmed this decreasing trend from Day 2 even at temperatures below $2^{\circ} \mathrm{C}$. This result underlines the importance of standardizing all IGR predictions to the Day 1 measurement-otherwise, predictions are likely to result in conservative estimates of growth. This could be more pronounced in warmer temperatures, such as in the South Georgia area, where IMP, or more generally, all physiological processes may operate on a shorter cycle compared to colder regions.

\section{Seasonal and regional trends in IGR}

The succession of spline curves across months provides a general account of seasonal trends in IGR (Fig. 4). Smaller krill generally exhibit higher growth rates and IGRs decrease with increasing size, although this size-based difference is reduced in the progression from summer to autumn. Krill in the 50 to $60 \mathrm{~mm}$ TL range showed very small IGRs for all months surveyed, tending towards negative values as the seasons progressed (especially for females). In the Indian Ocean sector, highest growth rates were observed in December, and they gradually decreased to minimum IGR values in April. This result matches the seasonal productivity in the region, as the peak in the ice edge phytoplankton bloom in the Indian Ocean around Prydz Bay is December to January (Jacques \& Fukuchi 1994); therefore, krill should exhibit maximum growth rates during this period. From December to February, variability in growth rates was high; however, for smaller krill $(<30 \mathrm{~mm})$, precision of means decreased, partly as a result of smaller sample sizes. In the southwest Atlantic sector, even though a high degree of variability was observed, high growth rates (e.g. IGR $\sim 0.2$ ) were observed in November and December; in contrast, IGRs were lower (mostly less than 0.1) in January and February. It is also worth noting that although krill in the Indian Ocean sector maintained their IGR at almost the same level from December to January (Fig. 4a), those in southwest Atlantic sector showed marked drop during the same period (Fig. 4b), indicating an earlier termination of the rapid growth period in the southwest Atlantic compared to the Indian Ocean sector.

Although the sample sizes and seasonal coverage in southwest Atlantic sector were limited, the generalizations that could be made regarding timing of growth indicated that the period of rapid growth in the southwest Atlantic sector occurs earlier than that for the Indian Ocean sector. We suggest that this period of rapid growth probably occurs in the September to November period, as was also suggested by Reid (2001) who compared the time progression of the mode of krill length frequency distributions around South Georgia using data obtained from the stomachs of fur seals. He suggested that the main growth period of krill around South Georgia may be from September to December, and that little growth occurs from January onwards. Siegel (1986) also indicated that krill growth off the Antarctic Peninsula seems to start as early as October and finishes in January. The slightly later start of growth in the Antarctic Peninsula region (October) compared to South Georgia (September) could be explained by a lower temperature regime for the former. The overall evidence strongly suggests that the timing of rapid growth in the southwest Atlantic sector is a few months earlier than in the Indian Ocean sector.

This early growth in the southwest Atlantic sector may be explained by the generally earlier occurrence of phytoplankton blooms at lower latitudes. Although krill are primarily herbivorous, they can also feed omnivorously under conditions of phytoplankton shortage (e.g. Hopkins \& Torres 1989), and are further reported to predate on copepods during summer at South Georgia (e.g. Atkinson \& Snyder 1997). Seasonal contribution of copepods as food source to krill growth is still unknown and certainly warrants further study. 


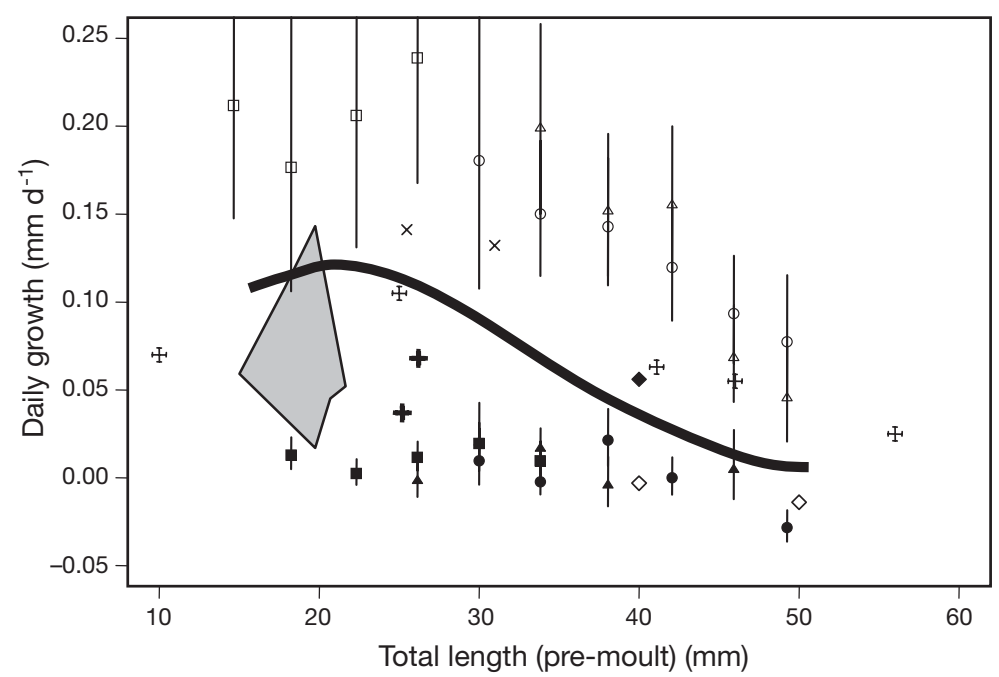

Fig. 8. Euphausia superba. Daily growth rates. Solid black line: Ikeda (1985); + laboratory data based on population growth (Polleck \& Denys 1982); grey box: IGR data (Ross et al. 2000); ‘: field LFD data (Kanda et al. 1982, McClachie 1988, Daly 1990); ×: laboratory data based on individual growth increment (Morris \& Keck 1984, Buchholz 1985); data (Quetin \& Ross 1991); $:$ IGR winter data (Quetin \& Ross 1991). December growth with SE bars from this study, $\square$ : juveniles; $\Delta$ : males; O: females. April growth with SE bars from this study, a: juveniles; $\boldsymbol{\Delta}$ : males; $\bullet$ : females

\section{Growth differences related to sex}

There was a significant difference between the growth rates of males and females, which was more obvious when expressed as daily growth rates (Figs. 4a \& 7a). Females showed significantly lower growth rates in January and February in the Indian Ocean sector, which coincided with the period of maximum reproduction (Hosie et al. 1988).

Reproduction is one of the most energetically demanding events in the life history of krill, and requires an enormous investment of resources particularly by females. After adult female krill become externally mature in the austral spring, it takes about 3 mo for ovaries to mature (Bargmann 1945, Quetin \& Ross 2001). Since the peak in reproduction in the Indian Ocean sector occurs in January to February, ovaries would start their maturation cycle as early as November. Therefore, from November through to the end of their reproduction period, females must invest a very significant proportion of their resources (external and/or internal) in reproductive processes (Nicol et al. 1995). This diversion of resources is likely to have a negative impact on somatic growth. However, in our observations, females showed significantly lower growth rates compared to males only in January and February. One possible explanation for this is that in the spring (November/December), the phytoplankton bloom associated with the retreating ice edge provides sufficient resources to support both somatic growth and maturation of their ovaries. After the peak of the spring bloom, there may no longer be sufficient food and female krill may have to divert most of their resources into ovarian maturation, resulting in lower IGRs and daily growth rates compared to males. If this is the case, the growth pattern of males and females should differ; therefore, the traditional method for age class determination using pooled length frequency distribution (LFD) analysis may give biased estimates depending on the sex ratio in the population surveyed. Furthermore, males may reach their maximum body size earlier than females, and might therefore have a shorter life span.

Alternatively, if females can increase the frequency of their moulting events during this period, they may not show such a pronounced reduction in growth for a given time period as that seen in their daily rates in Fig. 7, which assumes that IMP is the same for males and females given exposure to the same temperature regime. In fact, laboratory experiments have indicated a significantly shorter IMP for females once they have matured (mean IMP of approximately $29 \mathrm{~d}$ prior to maturity, compared to $25 \mathrm{~d}$ after maturation) (Thomas \& Ikeda 1987). Thus, smaller growth increments may be compensated to a certain extent by more frequent moults in females, to give an overall growth rate similar to that of males. However, this appears unlikely given the growth difference between males and females during the January to February period, with males demonstrating more than twice the mean daily growth rate of females for a length of $40 \mathrm{~mm}$ (Table 2). Sex-related differences in krill growth, particularly in the natural environment, should be a priority subject of future research.

\section{Comparison with daily growth rates from previous studies}

Predicted growth rates for the Indian Ocean sector showed large variability across the TL range and between sexes within the period December to April. Most previous values derived by traditional LFD analysis fell within the range of our predictions (Fig. 8). The one exception is where a $0.33 \mathrm{~mm} \mathrm{~d}^{-1}$ growth rate for $30 \mathrm{~mm}$ krill was observed by Clarke \& Morris (1983); however, this exceptionally high growth rate may have resulted from sampling different krill populations during short term LFD observations. 
Even if the assumption that sequential samples are taken from the same population is valid, a problem in using LFD analysis is that it only produces mean growth rates between consecutive samplings, which are generally several months apart (e.g. Rosenberg et al. 1986, Pakhomov 1995). This limits the ability of LFDs to provide, at best, growth trends between seasons. The IGR technique gives measurements of individual growth when the pulse of growth actually occurs (i.e. at moulting). This allows contemporaneous measurement of environmental variables, such as season and region, and population structure variables, such as sex and size, to be sampled and results in realistic season-dependent, sex-dependent, and sizedependent growth patterns from field data. The growth patterns obtained through IGR measurements confirmed results from some of previous studies, which indicated that wild krill show rapid growth over a shorter growth period earlier in their growing season. Our data and analyses also suggested a shorter period for rapid somatic growth in females compared to males.

IGRs measured by Quetin \& Ross (1991) showed 1.75 to $4.40 \%$ growth in length per moult which is equivalent to $0.056 \mathrm{~mm} \mathrm{~d}^{-1}$ for a $40 \mathrm{~mm}$ krill (Quetin et al. 1994). Other measurements based on growth increments per moult during the summer season also fell within our range (e.g. Buchholz 1991). Mid-winter IGRs measured in the Antarctic Peninsula region showed $2.03 \%$ negative growth for the krill population. This is equivalent to $-0.013 \mathrm{~mm} \mathrm{~d}^{-1}$ (40 $\left.\mathrm{mm} \mathrm{krill}\right)$ or $-0.016 \mathrm{~mm} \mathrm{~d}^{-1}$ (50 mm krill) assuming an IMP of $90 \mathrm{~d}$. This is at the lower end of the growth rates we obtained for $40 \mathrm{~mm}$ female krill $\left(-0.003 \mathrm{~mm} \mathrm{~d}^{-1}, \mathrm{SE}=\right.$ $0.010)$ and $50 \mathrm{~mm}$ female krill $\left(-0.014 \mathrm{~mm} \mathrm{~d}^{-1}, \mathrm{SE}=\right.$ 0.020) in April (Table 2). Ross et al. (2000) estimated growth rates of late furcillia and juvenile krill (seasonal growth rates of 0.072 to $0.082 \mathrm{~mm} \mathrm{~d}^{-1}$ ). The growth rates from individual experiments ranged from 0.02 to $0.13 \mathrm{~mm} \mathrm{~d}^{-1}$ for a size range of 12 to $24 \mathrm{~mm} \mathrm{krill}$.

Trends in Ross et al.'s (2000) growth estimates appeared to agree reasonably well with our results. However, a different calculation method for IGR in this study (standardising the IGR to Day 1 moult) compared to that used in their studies (average of IGRs over a $4 \mathrm{~d}$ period) probably accounted for the slightly wider range of daily growth rate esimates in our study, especially at higher rates of daily growth.

Ross et al. (2000) observed clear functional relationship between quantity and quality of food available and growth rate. Although our results were not accompanied by chlorophyll data, our seasonal growth patterns are likely to be due to seasonal trends in food availability, as well as to temperature trends and the physiological status of the krill.

\section{Future model refinements}

In the current model, we used temperature as the only predictor of IMP, based on the fact that temperature is known to be the most important extrinsic factor affecting IMP: in general, a rise in temperature shortens the IMP (Hartnoll 1982). However, in reality, IMP could also be affected by many other factors such as animal size, sex, maturity, and food supply etc (Hartnoll 1982). For example, a number of reports (e.g. Buchholz et al. 1996) showed increasing IMP for larger krill. If so, krill (and particularly smaller animals), may potentially show more dynamic growth than we have predicted due to more frequent moulting. In relation to sex and maturity, Buchholz et al. (1996) demonstrated longer IMP for mature females but Thomas \& Ikeda (1987) reported the opposite effect on IMP. Quality and quantity of food supply are also thought to affect IMP (Hartnoll 2001). Furthermore, IMP in laboratory conditions is always likely to be longer than in the wild. This implies that IMP in the wild is by no means as simple as was modeled in this study. Therefore, the effects and interactions of these factors on IMP certainly warrant furthur investigation.

The seasonal trend in IGR was thought to be due to the combined effect of seasonal changes in food condition and in temperature, coupled with the developmental history of krill. Delineation of the effects of these 2 external factors on IGR and IMP would allow us to simulate growth patterns of krill under different environmental conditions, and allow for more flexible and robust modelling. The effects of maturity stage and the interaction between IGR, IMP, and sex on growth should be further investigated and the incorporation of this interaction into the model should be considered in the future. There may be some trade-offs between IMP and IGR. In general, it is known that for crustaceans, a decreasing IMP (frequent moulting) accompanied by increasing temperature results in reduced IGR, but that net growth can still remain positive (Hartnoll 2001); however, this has not been corroborated for krill. Solving each of these questions through experiments in a controlled environment would contribute to a further understanding of krill biology, which could lead to improved population models.

We could not fully investigate the effect of DCM on IGR in the southwest Atlantic sector in this study because of the limited sample size, which resulted in many combinations of DCM with other predictive factors being absent from the dataset. This situation needs to be reassessed when a more comprehensive dataset from southwest Atlantic sector becomes available. 


\section{CONCLUSIONS}

Growth rate estimates based on IGR measurements combined with an appropriate statistical model for data summarisation revealed dynamic growth trends for krill across time, size, and sex. Because these estimates were based on growth measurements of individual animals, we believe that this pattern reflects what is happening in the natural environment. Growth rate estimates based on composite length frequency distributions without sex differentiation may be problematic. These findings also raise the possibility that the life span may differ between sexes. These are all critical questions that need to be answered before krill management models can be refined.

Acknowledgements. We express our gratitude to the captains and crews of RSV 'Aurora Australis' and RV 'Kaiyo-Maru' for their skill and support. Our gratitude extends to the many staff, graduate students, and undergraduate students who contributed to this work. We thank R. Ross, L. Quetin, F. Buchholz, and G. Tarling for useful discussions on the IGR method. We also thank the 4 anonymous reviewers for their helpful comments and improvements to the manuscript.

\section{LITERATURE CITED}

Atkinson A, Snyder R (1997) Krill-copepod interactions at South Georgia, Antarctica, I. Omnivory by Euphausia superba. Mar Ecol Prog Ser 160:63-76

Baker AdeC, Clark MR, Harris, MJ (1973) The N.I.O. combination net (RMT 1+8) and further development of Rectangular Midwater Trawls. J Mar Biol Assoc UK 53:176-184

Bargmann HE (1945) The development and life-history of adolescent and adult krill Euphausia superba. Discov Rep 23:103-176

Buchholz F (1985) Moult and growth in euphausiids. In: Siegfried WR, Condy PR, Laws RM (eds) Antarctic nutrient cycles and food webs. Springer-Verlag, Berlin, p 339-345

Buchholz F (1991) Moult cycle and growth of Antarctic krill Euphausia superba in the laboratory. Mar Ecol Prog Ser 69:217-229

Buchholz F, Watkins JL, Priddle J, Morris DJ, Ricketts C (1996) Moult in relation to some aspects of reproduction and growth in swarms of Antarctic krill, Euphausia superba. Mar Biol 127:201-208

Butler D, Cullis BR, Gilmour AR, Gogel BJ (2002) Spatial analysis mixed models: samm reference manual, training series QE02001. Queensland Department of Primary Industries, Toowoomba

Candy SG, Kawaguchi S (2006) Modelling growth of Antarctic krill. II. Novel approach to describing the growth trajectory. Mar Ecol Prog Ser 306:17-30 (this volume)

Clarke A, Morris DJ (1983) Towards an energy budget for krill: the physiology and biochemistry of Euphausia superba Dana. Polar Biol 2:69-86

Constable AJ, de la Mare WK (1996) A generalized model for evaluating yield and the long-term status of fish stocks under conditions of uncertainty. CCAMLR Sci 3:31-54

Daly K (1990) Overwintering development, growth, and feeding of larval Euphausia superba in the Antarctic marginal ice zone. Limnol Oceanogr 35:1564-1576
Hartnoll RG (1982) Growth. In: Abele LG (ed) Embryology, morphology, and genetics. The biology of Crustacea, Vol 2. Academic Press, New York, p 111-196

Hartnoll RG (2001) Growth in crustacea - twenty years on Hydrobiologia 449:111-122

Hoffman EE, Lascara CM (2000) Modeling the growth dynamics of Antarctic krill Euphausia superba. Mar Ecol Prog Ser 194:219-231

Hollander E (2001) Investigation of growth measurements for Antarctic krill, Euphausia superba. Honours thesis, University of Tasmania, Hobart

Hopkins TL, Torres JJ (1989) Midwater food web in the vicinity of a marginal ice zone in the Western Weddell Sea. Deep-Sea Res 36:543-560

Hosie GW, Ikeda T, Stolp M (1988) Distribution, adundance and population structure of the Antarctic krill (Euphausia superba Dana) in the Prydz Bay Region, Antarctica. Polar Biol 8:213-224

Ikeda T (1985) Life history of Antarctic krill Euphausia superba: a new look from an experimental approach. Bull Mar Sci 37:599-608

Ikeda T (1987) Mature Antarctic krill (Euphausia superba Dana) grown from eggs in the laboratory. J Plankton Res 9:565-569

Ikeda T, Dixon P (1982) Body shrinkage as a possible overwintering mechanism of the Antarctic krill, Euphausia superba Dana. J Exp Mar Biol Ecol 62:143-151

Ikeda T, Dixon P, Kirkwood J (1985) Laboratory observations on moulting, growth and maturation in Antarctic krill (Euphausia superba Dana). Polar Biol 4:1-18

Insightful (2002) S-plus 6 supplement for Windows. Insightful Corporation, Seattle, WA

Jacques G, Fukuchi M (1994) Phytoplankton of the Indian Antarctic Ocean. In: El-Sayed S (ed) Southern Ocean ecology: the BIOMASS perspective. Cambridge University Press, Cambridge, p 63-78

Kanda K, Takagi K, Seki Y (1982) Movement of the larger swarms of Antarctic krill Euphausia superba off Enderby Land during 1976-1977 season. J Tokyo Univ Fish 68:24-42

Mauchline J (1980) Measurement of body length of Euphausia superba Dana. BIOMASS Handbook No 4

McClachie S (1988) Food-limited growth of Euphausia superba in Admiralty Bay, South Shetland Islands, Antarctica. Cont Shelf Res 8:329-345

McCullagh P, Nelder JA (1989) Generalized linear models, 2nd edn. Chapman \& Hall, London

Morris DJ, Keck A (1984) The time course of the moult cycle and growth of Euphausia superba in the laboratory. A preliminary study. Meeresforsch 30:94-100

Murano M, Segawa S, Kato M (1979) Moult and growth of the Antarctic krill in the laboratory. Trans Tokyo Univ Fish 3: 99-106

Nicol S (2000) Understanding krill growth and aging: the contribution of experimental studies. Can J Fish Aquat Sci 57: 168-177

Nicol S, Stolp M, Cochran T, Geijsel P, Marshall J (1992) Growth and shrinkage of Antarctic krill Euphausia superba from the Indian Ocean sector of the Southern Ocean during summer. Mar Ecol Prog Ser 89:175-181

Nicol S, de la Mare WK, Stolp M (1995) The energetic cost of egg production in Antarctic krill (Euphausia superba Dana). Antarct Sci 7:25-30

Pakhomov EA (1995) Demographic studies of Antarctic krill Euphausia superba in the Cooperation and Cosmonaut Seas (Indian Ocean sector of the Southern Ocean). Mar Ecol Prog Ser 119:45-61

Platt RW, Leroux BG, Breslow N (1999) Generalized linear 
mixed models for meta-analysis. Stat Med 18:643-654

Poleck TP, Denys CJ (1982) Effect of temperature on the moulting, growth and maturation of the Antarctic krill Euphausia superba (Crustacea: Euphausiacea) under laboratory conditions. Mar Biol 70:255-265

Quetin LB, Ross RM (1991) Behavioural and physiological characteristics of the Antarctic krill, Euphausia superba. Am Zool 31:49-63

Quetin LB, Ross RM (2001) Environmental variability and its impact on the reproductive cycle of Antarctic krill. Am Zool 41:74-89

Quetin LB, Ross RM, Clarke A (1994) Krill energetics: seasonal and environmental aspects of the physiology of Euphausia superba. In: El-Sayed S (ed) Southern Ocean ecology: the BIOMASS perspective. Cambridge University Press, Cambridge, p 165-184

Reid K (2001) Growth of Antarctic krill Euphausia superba at South Georgia. Mar Biol 138:57-62

Rosenberg AA, Beddington JR, Basson M (1986) Growth and longevity of krill during the first decade of pelagic whaling. Nature 324:152-154

Editorial responsibility: Otto Kinne (Editor-in-Chief), Oldendorf/Luhe, Germany
Ross RM, Quetin LB (2003) Working with living krill-the people and the places. Mar Freshw Behav Physiol 36(4): 207-228

Ross RM, Quetin LB, Baker KS, Vernet M, Smith RC (2000) Growth limitation in young Euphausia superba under field conditions. Limnol Oceanogr 45:31-43

Siegel V (1986) Untersuchungen zur Biologie des antarktischen Krill, Euphausia superba, im Bereich der Bransfield Straße und angrenzender Gebiete. Mitt Inst Seefish 38:1-244

Thomas PG, Ikeda T (1987) Sexual regression, shrinkage, rematuration and growth of spent female Euphausia superba in the laboratory. Mar Biol 95:357-363

Verbyla AP, Cullis BR, Kenward MG, Welham SJ (1999) The analysis of designed experiments and longitudinal data using smoothing splines (with discussion). Appl Stat 48: 269-311

Whitehouse MJ, Priddle J, Symon C (1996) Seasonal and annual change in seawater temperature, salinity, nutrient and chlorophyll a distributions around South Georgia, South Atlantic. Deep-Sea Res I 43:425-443

Submitted: May 26, 2005; Accepted: October 13, 2005

Proofs received from author(s): December 7, 2005 